\title{
Fast-current-heating devices to study in situ phase formation in metallic glasses by using high-energy synchrotron radiation
}

Cite as: Rev. Sci. Instrum. 91, 073901 (2020); https://doi.org/10.1063/5.0005732

Submitted: 24 February 2020 . Accepted: 12 June 2020 . Published Online: 02 July 2020

Jiri Orava (D), Konrad Kosiba (D), Xiaoliang Han, Ivan Soldatov, Olof Gutowski, Oleh Ivashko (D), Ann-Christin Dippel, Martin v. Zimmermann, André Rothkirch, Jozef Bednarcik, Uta Kühn, Hartmut Siegel, Steffen Ziller, Alexander Horst, Karsten Peukert, Ralf Voigtländer, Dirk Lindackers, and Ivan Kaban

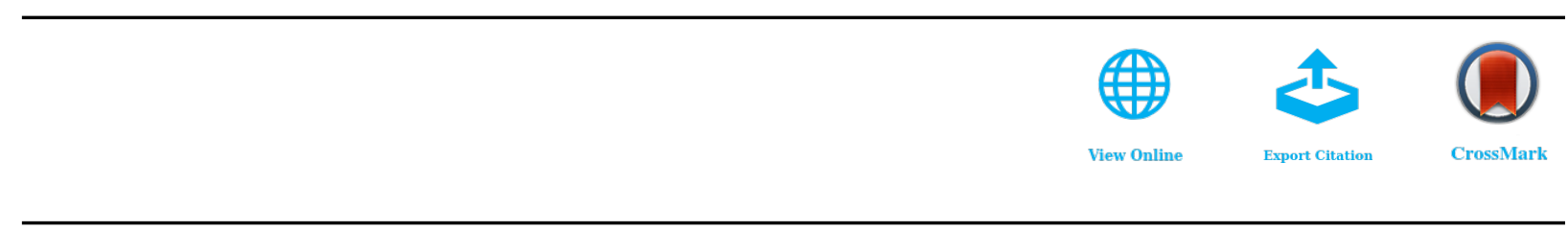

\section{ARTICLES YOU MAY BE INTERESTED IN}

A laser powder bed fusion system for in situ x-ray diffraction with high-energy synchrotron radiation

Review of Scientific Instruments 91, 075104 (2020); https://doi.org/10.1063/1.5143766

Combined gas electron diffraction and mass spectrometric experimental setup at Bielefeld University

Review of Scientific Instruments 91, 073103 (2020); https://doi.org/10.1063/5.0012071

Visible pump-mid infrared pump-broadband probe: Development and characterization of a three-pulse setup for single-shot ultrafast spectroscopy at $50 \mathrm{kHz}$

Review of Scientific Instruments 91, 073106 (2020); https://doi.org/10.1063/5.0016362

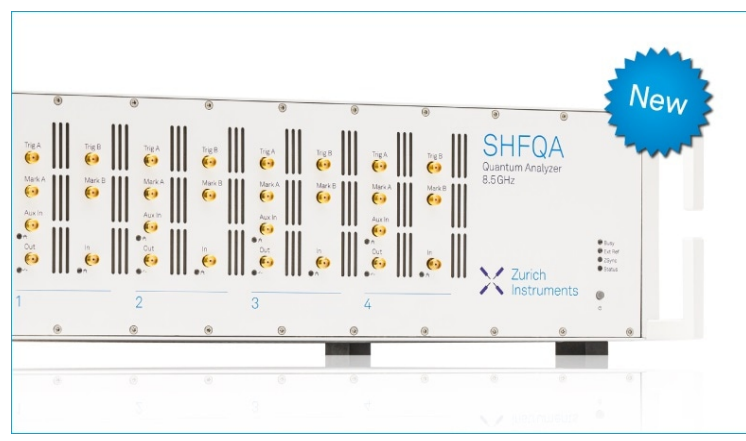

\section{Your Qubits. Measured.}

Meet the next generation of quantum analyzers

- Readout for up to 64 qubits

- Operation at up to $8.5 \mathrm{GHz}$,

Find out more

- Signal optimization with minimal latency 


\title{
Fast-current-heating devices to study in situ phase formation in metallic glasses by using high-energy synchrotron radiation
}

Cite as: Rev. Sci. Instrum. 91, 073901 (2020); doi: 10.1063/5.0005732

Submitted: 24 February 2020 - Accepted: 12 June 2020 •

Published Online: 2 July 2020

Jiri Orava, , a) (D) Konrad Kosiba, ${ }^{1, a)}$ (D) Xiaoliang Han, ${ }^{1}$ Ivan Soldatov, ${ }^{1}$ Olof Gutowski, ${ }^{2}$ Oleh Ivashko,

Ann-Christin Dippel, ${ }^{2}$ Martin v. Zimmermann, ${ }^{2}$ André Rothkirch, ${ }^{2}$ Jozef Bednarcik, ${ }^{2, b)}$ Uta Kühn, Hartmut Siegel, ${ }^{1}$ Steffen Ziller, ${ }^{1}$ Alexander Horst, ${ }^{1}$ Karsten Peukert, ${ }^{1}$ Ralf Voigtländer, ${ }^{1}$ Dirk Lindackers, and Ivan Kaban

\author{
AFFILIATIONS \\ ${ }^{1}$ IFW Dresden, Helmholtzstraße 20, Dresden 01069, Germany \\ ${ }^{2}$ Deutsches Elektronen-Synchrotron DESY, Notkestraße 85, Hamburg 22603, Germany
}

\begin{abstract}
a) Authors to whom correspondence should be addressed: j.orava@ifw-dresden.de and k.kosiba@ifw-dresden.de b) Present address: Department of Condensed Matter Physics, Institute of Physics, P.J. Safarik University in Kosice, Park Angelinum 9, Kosice 04154, Slovakia.
\end{abstract}

\begin{abstract}
Details of fast-resistive-heating setups, controlled heating ranging from $\sim 10^{1} \mathrm{~K} \mathrm{~s}^{-1}$ to $\sim 10^{3} \mathrm{~K} \mathrm{~s}^{-1}$, to study in situ phase transformations (on heating and on cooling) in metallic glasses by high-energy synchrotron $\mathrm{X}$-ray diffraction are discussed. Both setups were designed and custom built at the Leibniz Institute for Solid State and Materials Research Dresden (IFW Dresden) and have been implemented at the P02.1 Powder Diffraction and Total Scattering Beamline and the P21.1 Swedish Materials Science Beamline at PETRA III storage ring, DESY, Hamburg. The devices are interchangeable at both beamlines. Joule heating is triggered automatically and is timed with the incident beam and detector. The crystallization process can be controlled via a feedback circuit by monitoring the change in the time-dependent resistivity and temperature of glasses. Different ambient atmospheres, such as vacuum and inert gases (He and Ar), can be used to control oxidation and cooling. The main focus of these devices is on understanding the crystallization mechanism and kinetics in metallic glasses, which are brittle and for which fast heating gives defined glass-crystal composites with enhanced plasticity. As an example, phase-transformation sequence(s) in a prototyped $\mathrm{Cu}-\mathrm{Zr}$-based metallic glass is described on heating, and a crystalline phase beneficial to the plasticity is identified.
\end{abstract}

Published under license by AIP Publishing. https://doi.org/10.1063/5.0005732

\section{INTRODUCTION}

Metallic glasses (MGs) have some interesting mechanical properties, for example, high toughness and hardness, large fracture strength, and low mechanical dumping, ${ }^{1}$ which make them stand out from other traditional metallic-based alloys. Nevertheless, MGs suffer from poor compressive plasticity and tensile ductility, which limit their application as structural materials. Among other methods to improve the mechanical properties of $\mathrm{MGs},{ }^{2-5}$ forming glasscrystal composites has given materials with significantly enhanced plasticity (up to $\sim 10 \%$ plastic strain can be achieved ${ }^{6}$ ), ductility, and with higher toughness than the corresponding glass. ${ }^{9-11}$ In order to control and tune the mechanical properties of the resulting MG-crystal composites, the crystallization mechanism and kinetics of phase formation have to be understood. The final composite microstructure, phase types, crystal size, and their distribution are better controlled on heating the glass, rather than on cooling the liquid, which allows for tuning the crystallization mechanism by changing the heating rate, $\Phi$.

$\mathrm{A} \mathrm{Cu}-\mathrm{Zr}$-based family of metallic glasses has often been studied in theoretical and experimental works because of its good glassforming ability and interesting features of the crystalline phases formed upon annealing. The cubic B2-CuZr crystalline phase (space group $P m \overline{3} m$ and a prototype $\mathrm{CsCl}$ structure) is known to be 
beneficial to plasticity, but it is metastable at low temperatures; the stable temperature is $\sim 900 \mathrm{~K}$ and above. ${ }^{12}$ For a $\mathrm{Cu}-\mathrm{Zr}$-Al-based glassy family, heating rates of $\Phi \sim 10^{2} \mathrm{~K} \mathrm{~s}^{-1}$ and higher are needed to suppress the unwanted formation of the brittle low-temperature phases, such as $\mathrm{Cu}_{10} \mathrm{Zr}_{7}$ (space group $\mathrm{C} 2 \mathrm{ca}$ ) and $\mathrm{CuZr}_{2}$ (space group $\mathrm{I} / \mathrm{mmm}$ ), and to directly go into the crystallization regime in which the ductile B2 phase is dominantly formed. ${ }^{13}$ Therefore, heating cells with heating rates varying from $\sim 10 \mathrm{~K} \mathrm{~min}^{-1}$ to $\sim 10^{2} \mathrm{~K} \mathrm{~min}^{-1}$ are not sufficiently fast. ${ }^{14-16}$ To access higher heating rates, the so-called flash-annealing methods utilizing electric current passing through the sample, named resistive or Joule heating, and eddy currents induced by a high-frequency external magnetic field (induction heating) can be used.

Küchemann and Samwer ${ }^{20}$ have presented a capacitancedischarge-heating device, designed after the work of Johnson et al., ${ }^{21}$ which gave new insights into in situ structural evolution and crystallization of a Zr-based metallic-glass ribbon at the beamline P07 at PETRA III, DESY, in air. Given the capacitance of $1 \mathrm{mF}$ and a built-in discharge circuit resistance, heating was intentionally limited to extremely high rates of $\sim 10^{5} \mathrm{~K} \mathrm{~s}^{-1}$ to $10^{6} \mathrm{~K} \mathrm{~s}^{-1}$ only. Also, dominant formation of $\mathrm{ZrO}_{2}$ was observed at highest heating rates because of the ambient atmosphere. The oxidation of Vit106a glass was later suppressed by doing the capacitance-discharge heating in an argon atmosphere, and structural changes on fast heating were studied at the beamline 11-ID-C at the Advanced Photon Source of the Argonne National Laboratory. ${ }^{22}$ A combination of conventional calorimetry, DC heating, and the above-noted capacitance-discharge heating was applied by Küchemman et al. ${ }^{23}$ to study the kinetics of the glass-transition temperature, $T_{\mathrm{g}}$, and the onset of crystallization, $T_{\mathrm{x}}$, for $\Phi$ ranging from $10^{-1} \mathrm{~K} \mathrm{~s}^{-1}$ to $10^{6} \mathrm{~K} \mathrm{~s}^{-1}$ in $\mathrm{Zr}_{65} \mathrm{Cu}_{27.5} \mathrm{Al}_{7.5}$ metallic glass. Note that there have been a variety of fast-resistiveheating devices constructed to study the influence of crystallization on magnetic properties of soft-magnetic Fe-based glasses. ${ }^{17,18,24-26}$

Here, we describe and demonstrate the capabilities of two current-induced-heating devices, designed and constructed at the Leibniz Institute for Solid State and Materials Research Dresden (IFW Dresden), to study in situ phase formation at controlled conditions (heating/cooling rate, temperature, and atmosphere). One device is intended for controlled DC heating of ribbons and the other device is for pulsed heating of bulk-metallic glasses (BMGs). The devices have been implemented at the P02.1 Powder Diffraction and Total Scattering Beamline and at the P21.1 side branch of the Swedish Materials Science Beamline at PETRA III storage ring, DESY, Hamburg. Third-generation synchrotron radiation sources are particularly of interest for in situ studies of structural changes and associated physical responses in a variety of materials. ${ }^{27}$ The beamline P02.1 is operated at a fixed photon energy of $60 \mathrm{keV}$ and is suitable for high-resolution high-energy powder diffraction. ${ }^{28}$ The recently built P21.1 beamline operates at $52 \mathrm{keV}, 85 \mathrm{keV}$, and 100 $\mathrm{keV}$ and is dedicated to high-energy $\mathrm{x}$-ray single-crystal diffraction and total scattering.

Although the main focus here is on demonstrating case studies of crystallization with the aim to form MG-crystal composites, the custom-built devices can also be used to study fundamental properties of glass-forming liquids, for example, continuous-heatingand continuous-cooling-transformation diagrams, in situ structural changes in glasses and supercooled liquids, nucleation and crystalgrowth kinetics, and influence of thermal history on glass' properties by rejuvenating/relaxing glasses via glass-supercooled liquid-glass cycling - all of these are beyond the scope of this instrumental review paper.

\section{DEVICES' DESIGN}

Figure 1 shows schematics of the fast-heating setups custom built at IFW Dresden for probing crystallization in [(a) and (b)] metallic-glass ribbons and [(c) and (d)] bulk-metallic glasses at DESY. Photographs of the devices are presented in Fig. 2: Fig. 2(a) shows the device for ribbons and that in Fig. 2(b) is for BMGs.

\section{A. Ribbons}

Melt-spun ribbons $(\approx 30 \mu \mathrm{m}$ thick, $\sim 2 \mathrm{~mm}$ wide), cut into $\approx 5.4 \mathrm{~cm}$ long pieces, $\approx 3 \mathrm{~cm}$ of an active length, are resistively heated in a constant-current mode by using a Delta Elektronika SM 5230 power supply. The sample surface temperature is monitored by using a LumaSense IGA 320/23-LO pyrometer with a temporal resolution of $2 \mathrm{~ms}$ in analog mode, which is calibrated on the known melting point of the glass-measured independently by hightemperature calorimetry. All monitor and signal data are analyzed and collected by a digital analog converted USB-6211 (National Instruments; a sampling rate of up to $250 \mathrm{kS} \mathrm{s}^{-1}$ ) and processed in Labview based software on PC. In the case study presented in Sec. III, data were acquired at a rate of $48 \mathrm{kS} \mathrm{s}^{-1}$ with subsequent averaging, reducing the sample rate down to $4 \mathrm{kS} \mathrm{s}^{-1}$. Before sample resistance is directly measured by the acquisition card, the voltage drop along the sample is reduced by a voltage divider with a reduction ratio of $\frac{1}{4}$ to adjust it to the card input range at high heating currents.

\section{B. Bulk-metallic glasses}

Heating of a BMG sample, $\approx 10 \mathrm{~mm}$ long, $\approx 500 \mu \mathrm{m}$ thick, and $\approx 1.5 \mathrm{~mm}$ wide, is done via an electrical-current pulse generated by a power supply unit (Magna-Power SL 25-60 equipped with the Option + HS 1,5-15) connected to a signal wave generator (Rohde \& Schwarz HMF2525). The surface temperature is monitored by a LumaSense IGAR 12LO pyrometer (temporal resolution of $2 \mathrm{~ms}$ ), which is calibrated using a type $\mathrm{T}$ thermocouple. The current is measured via a current probe (Chauvin Arnoux E3) with switching electronics that transform it into a voltage signal. A datalogger (FLUKE NetDAQ 2645A) with a sampling rate of $1 \mathrm{kS} \mathrm{s}^{-1}$ is utilized to record temperature, electrical current, and voltage signals.

For both setups, a high-speed pyrometer is focused on the sample through a $\mathrm{KBr}$ window and coincides with the primary $\mathrm{x}$-ray beam (Figs. 1 and 2), which passes through a polyimide-foil window (thickness of $250 \mu \mathrm{m}$ ). The output windows are made of borosilicate glass (100 $\mathrm{mm}$ in a diameter and $5.5 \mathrm{~mm}$ thick), thermally strengthened similar to DIN 7080 from Herberts Industrieglas $\mathrm{GmbH} \& \mathrm{Co}$, Wuppertal, Germany, for the ribbon setup, and of polyimide foil (23 $\mathrm{mm}$ in a diameter and $250 \mu \mathrm{m}$ thick) for the BMG setup; lids are not shown in the photographs (Fig. 2). Typically, a sample is kept in vacuum when heated, but the presence of a gas inlet allows for different atmospheres, commonly $\mathrm{Ar}$ and $\mathrm{He}$, to be maintained in the closed chamber to prevent oxidation, typically dominated by the formation of $\mathrm{ZrO}_{2}$ for $\mathrm{Cu}-\mathrm{Zr}$-based glasses, ${ }^{30}$ and to control the cooling rate. A typical controlled heating rate ranges from 
(a)

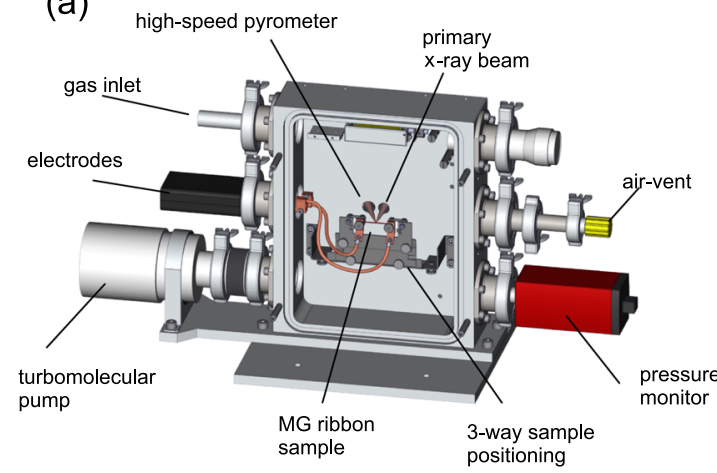

(b)

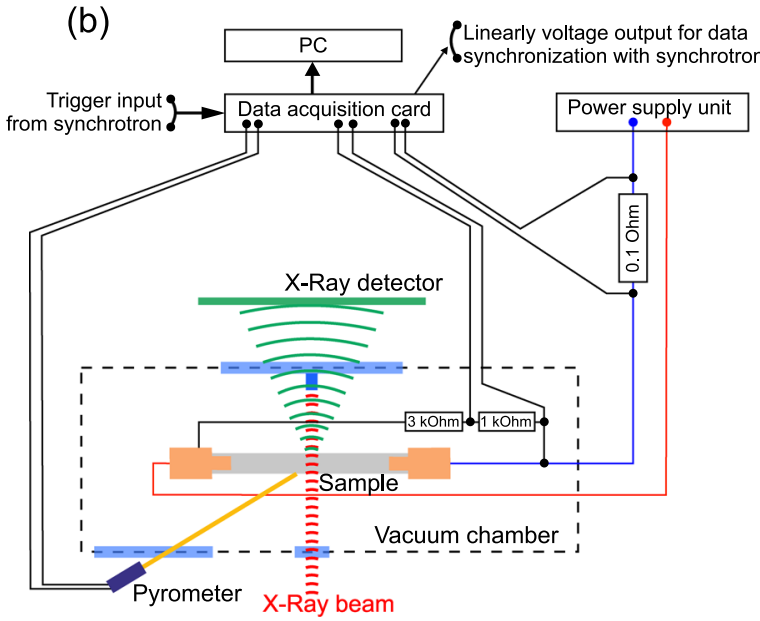

(c)

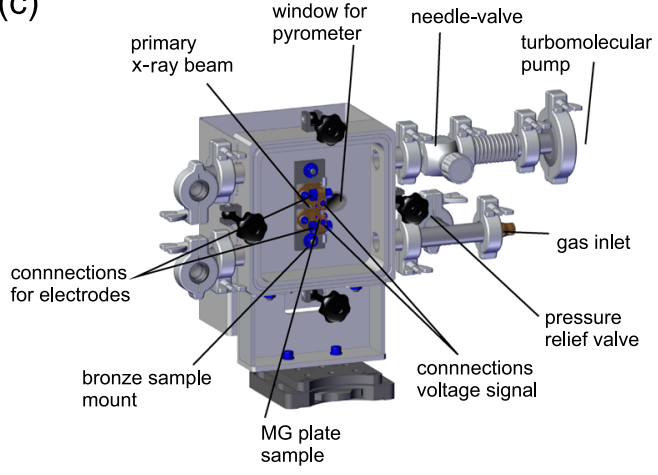

(d)

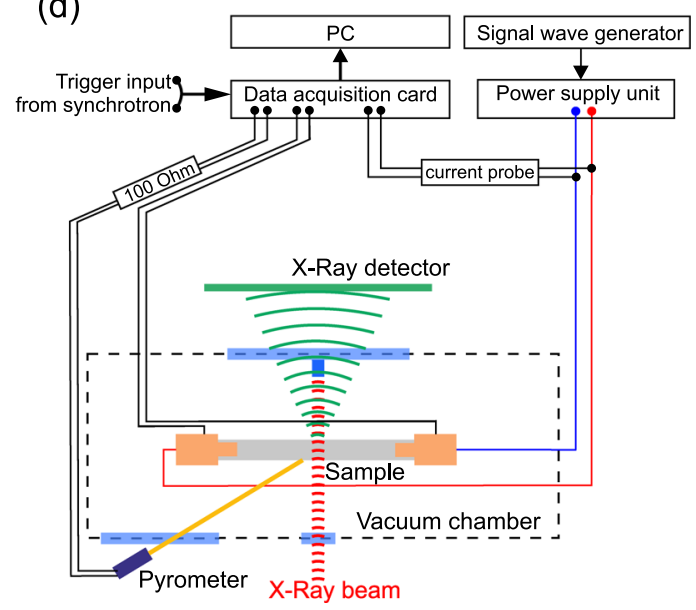

FIG. 1. Schematics of the fast-current-heating devices designed and custom built at IFW Dresden for in situ high-energy x-ray studies of phase transformations in metallicglass (MG): [(a) and (b)] ribbons ( $\approx 3 \mathrm{~cm}$ of an active length) and [(c) and (d)] bulk samples ( $\approx 10 \mathrm{~mm}$ long, $\approx 500 \mu \mathrm{m}$ thick, and $\approx 1.5 \mathrm{~mm}$ wide) in a transmission mode at DESY, Hamburg. For clarity, parts in (a) and (c) do not show the air-tight lid used during the experiments. Please refer to Fig. 2 for scaling.

$\sim 50 \mathrm{~K} \mathrm{~s}^{-1}$ to $\sim 10^{3} \mathrm{~K} \mathrm{~s}^{-1}$ for ribbons and between $\approx 50 \mathrm{~K} \mathrm{~s}^{-1}$ and $\approx 3000 \mathrm{~K} \mathrm{~s}^{-1}$ for BMGs. For ribbons, a heating up to $10^{5} \mathrm{~K} \mathrm{~s}^{-1}$ can be achieved to study, for example, crystallization kinetics and structural changes, but the sample temperature is difficult to control, and such fast heating is impractical for composites formation. An initial cooling rate is about $200-300 \mathrm{~K} \mathrm{~s}^{-1}$ in a vacuum of $10^{-4} \mathrm{mbar}$ for both devices. Additionally, both devices can be equipped with an external high-speed video camera accessory, for example, a FASTCAM SA3 model $120 \mathrm{~K}$ with a frame rate of up to $120000 \mathrm{fps}$, to study in situ the propagation of a thermal front for heated samples. The camera can be triggered automatically from extern and synchronized with heating.
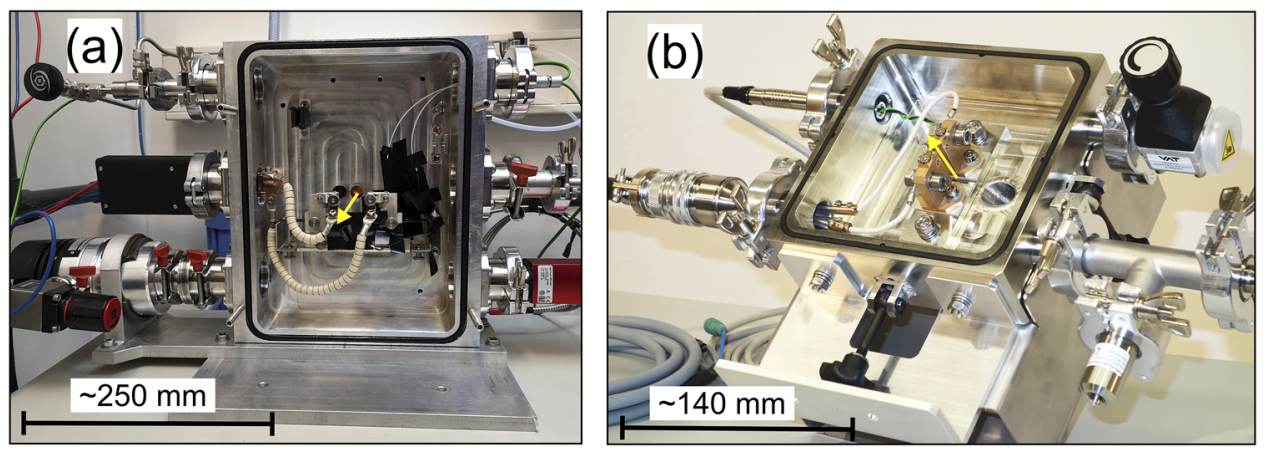

FIG. 2. Photographs of the fast-currentinduced heating devices for (a) ribbons and (b) bulk-metallic glasses. The x-ray beam direction is highlighted by the yellow arrows. Please refer to Fig. 1 [panels (a) and (b)] for the description of the individual components. 


\section{CASE STUDY OF PHASE-TRANSFORMATIONS IN CU-Zr-BASED GLASSES}

\section{A. Sample preparation}

Pre-alloys of $\mathrm{Cu}_{47.5} \mathrm{Zr}_{47.5} \mathrm{Al}_{4.0} \mathrm{Co}_{0.5}$ (at. \%) and $\mathrm{Cu}_{44} \mathrm{Zr}_{44} \mathrm{Al}_{8} \mathrm{Hf}_{2}$ $\mathrm{Co}_{2}$ (at. \%) were prepared from high-purity elements ( $\geq 99.99 \%$ ) by arc-melting in a Ti-gettered $\mathrm{Ar}$ atmosphere. Each ingot was remelted three times to ensure chemical homogeneity. $\mathrm{Cu}_{47.5} \mathrm{Zr}_{47.5}$ $\mathrm{Al}_{4.0} \mathrm{Co}_{0.5}$ alloy was melt-spun as a ribbon and $\mathrm{Cu}_{44} \mathrm{Zr}_{44} \mathrm{Al}_{8} \mathrm{Hf}_{2} \mathrm{Co}_{2}$ alloy was cast into bulk-metallic-glass plates. The ribbon, $\approx 30 \mu \mathrm{m}$ thick and $\sim 2 \mathrm{~mm}$ wide, was spun from a master-alloy melt $(T \sim 1320$ $\mathrm{K}$ ) on a $\mathrm{Cu}$ wheel rotating at $29 \mathrm{~m} \mathrm{~s}^{-1}$. The plates (with a width of $\approx 10 \mathrm{~mm}$, a thickness of $\approx 1.5 \mathrm{~mm}$, and a length of $\approx 55 \mathrm{~mm}$ ) of $\mathrm{Cu}_{44} \mathrm{Zr}_{44} \mathrm{Al}_{8} \mathrm{Hf}_{2} \mathrm{Co}_{2}$ were prepared via suction casting in a watercooled copper mold (Edmund Bühler) under a Ti-gettered Ar atmosphere. The as-cast plates were cut into $\approx 10 \mathrm{~mm}$ long pieces.

\section{B. Synchrotron experiments}

In situ high-energy synchrotron x-ray diffraction (XRD) carried out in a transmission mode is shown here to demonstrate the devices performance and properties. In most experiments, heating is done in a vacuum of $10^{-4} \mathrm{mbar}$ (if not specified otherwise).

For ribbons, high-energy $\mathrm{x}$-ray diffraction was done at the P21.1 beamline at DESY (wavelength $0.1204 \AA$ and a beam size of $\approx 900$ $\times 900 \mu \mathrm{m}^{2}$ ). Scattered intensities were captured by using a hybrid pixel Dectris PILATUS3 X CdTe 2M detector (pixel size 172 $\times 172 \mu \mathrm{m}^{2}$ ) operated at $250 \mathrm{~Hz}$. Diffractograms were derived from the recorded $2 \mathrm{D}$ patterns by azimuthal integration using the Fit2D v17.006 software. ${ }^{3}$

For $B M G$ s, prior to measurements, the as-cast glassy plates were grinded down to a uniform thickness of $\approx 500 \mu \mathrm{m}$; the final sample was then $\approx 10 \mathrm{~mm}$ long and $\approx 1.5 \mathrm{~mm}$ wide. High-energy $\mathrm{x}$-ray diffraction was performed at the P02.1 beamline at DESY (wavelength of $0.2066 \AA$ and a beam size of $\approx 500 \times 500 \mu \mathrm{m}^{2}$ ). Diffraction patterns were derived from the recorded $2 \mathrm{D}$ data of a Lambda $2 \mathrm{M}$ GaAs detector (X-Spectrum, pixel size $55 \times 55 \mu \mathrm{m}^{2}$ ). The $2 \mathrm{D}$ data were taken at a frame rate of $100 \mathrm{~Hz}$. The collected 2D patterns were integrated using the DESY p02_processing_tool software (version $0.26 \mathrm{~m} \_$beta11; May 11, 2018) package developed by one of the authors of this paper. ${ }^{34}$ Both resistive-heating setups are interchangeable at both beamlines.

Heating of the glasses can readily be controlled by the applied power as consistent with Joule heating, $P=I^{2} \times R$, where $I$ is the applied current and $R$ is the sample resistance. In a constant-current mode, the heating rate scales linearly with the applied power up to $10^{3} \mathrm{~K} \mathrm{~s}^{-1}$, as shown in Fig. 3 for ribbons. For heating at $\sim 1000 \mathrm{~K} \mathrm{~s}^{-1}$ and slower, the rate is non-linear, and it is difficult to transpose $T_{\mathrm{g}}$, and $T_{\mathrm{x}}$ on the same heating curve. An effective heating rate is estimated by assuming linear heating between room temperature and $T_{\mathrm{x}}$. This provides $\Phi$ values comparable with the literature ${ }^{6,13}$ and consistent with ultra-fast scanning calorimetry. ${ }^{35,36}$ For ribbons, a fast $\sim 250 \mathrm{~ms}$ probing period is introduced to determine the sample's resistance before heating. The known resistance is then used as an input parameter to match heating rates, applied power, of different samples in a constant-current mode.

The glass-transition temperature, $T_{\mathrm{g}}$, and the temperature corresponding to the onset of crystallization, $T_{\mathrm{x}}$, can readily be

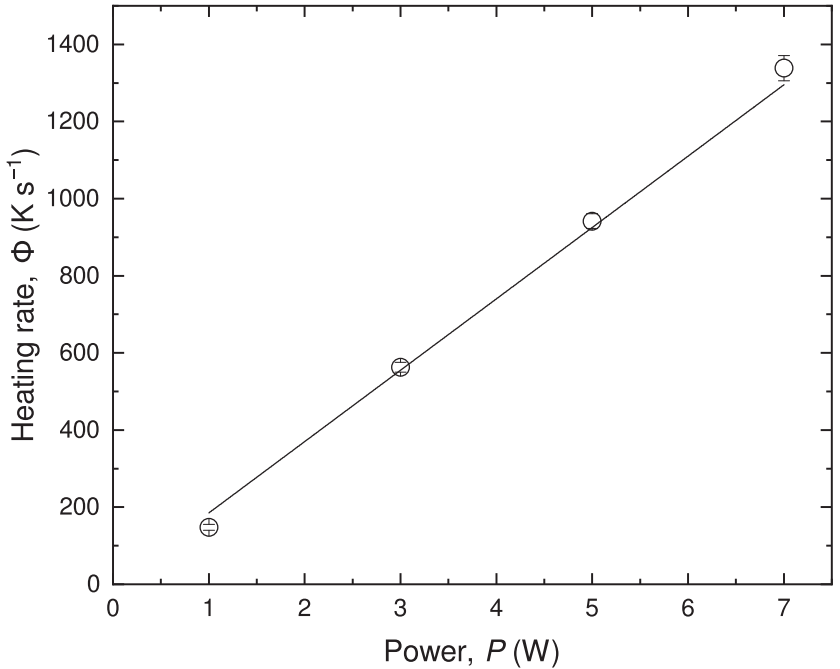

FIG. 3. Linear dependence of an effective heating rate, $\Phi$, on the applied power $P$, for the $\mathrm{Cu}_{47.5} \mathrm{Zr}_{47.5} \mathrm{Al}_{4.0} \mathrm{C}_{0.5}$ glassy ribbon in the typical range of heating rates used for composites formation and in a vacuum of $10^{-4} \mathrm{mbar}$. The solid line shows a linear fit to the experimental data points $\left(R^{2}=0.9979\right)$.

measured by monitoring the temporal evolution of resistance and sample temperature [Figs. 4(a) and 4(c)]. An endothermic glass transition is manifested by the change in the slope of the evolving heat monitored by the pyrometer, $t \approx 390 \mathrm{~ms}, T \approx 750 \mathrm{~K}$, for the $\mathrm{Cu}_{47.5} \mathrm{Zr}_{47.5} \mathrm{Al}_{4.0} \mathrm{Co}_{0.5}$ ribbon [Figs. 4(a)] and, $t \approx 3850 \mathrm{~ms}, T \approx 745 \mathrm{~K}$, for the $\mathrm{Cu}_{44} \mathrm{Zr}_{44} \mathrm{Al}_{8} \mathrm{Hf}_{2} \mathrm{Co}_{2}$ BMG [Fig. 4(c)]. A sharp drop in the resistance, at $t_{\mathrm{x}} \approx 625 \mathrm{~ms}, T_{\mathrm{x}} \approx 890 \mathrm{~K}$ [Fig. 4(a)] and at $t_{\mathrm{x}} \approx 4950 \mathrm{~ms}$, $T_{\mathrm{x}} \approx 910 \mathrm{~K}$ [Fig. 4(c)], marks the onset of crystallization of the $\mathrm{Cu}_{47.5} \mathrm{Zr}_{47.5} \mathrm{Al}_{4.0} \mathrm{Co}_{0.5}$ ribbon and that of the $\mathrm{Cu}_{44} \mathrm{Zr}_{44} \mathrm{Al}_{8} \mathrm{Hf}_{2} \mathrm{Co}_{2}$ $\mathrm{BMG}$, respectively. There are limited studies of independent measurements of $T_{\mathrm{g}}$ and $T_{\mathrm{x}}$ at such high heating rates. Cheng et al. ${ }^{35}$ measured $T_{\mathrm{g}}$ and $T_{\mathrm{x}}$ for $\mathrm{Cu}_{47.5} \mathrm{Zr}_{47.5} \mathrm{Al}_{5.0}$ alloy by ultra-fast scanning calorimetry. For the present heating at $\Phi \approx 950 \mathrm{~K} \mathrm{~s}^{-1}$ [Fig. 4(a)], $T_{\mathrm{g}}$ and $T_{\mathrm{x}}$ conform to $T_{\mathrm{g}}=770 \mathrm{~K}$ and $T_{\mathrm{x}}=900 \mathrm{~K}$ reported at $\Phi=1000 \mathrm{~K} \mathrm{~s}^{-1} \cdot 35$ Although the composition studied by Cheng et $a l .{ }^{35}$ differs from the present study, Miao et al. ${ }^{36}$ have shown that for the equimolar CuZr, calorimetric $T_{\mathrm{g}}$ and $T_{\mathrm{x}}$ are nearly unchanged when the glass is alloyed with 5 at.\% of Co; measured by ultra-fast heating calorimetry at $\Phi=3000-4000 \mathrm{~K} \mathrm{~s}^{-1}$. For bulk $\mathrm{Cu}_{44} \mathrm{Zr}_{44} \mathrm{Al}_{8} \mathrm{Hf}_{2} \mathrm{Co}_{2}$, the measured $T_{\mathrm{g}}$ and $T_{\mathrm{x}}$ are in good agreement with the results published on the same alloy in Refs. 6 and 13.

For the ribbon, the use of the voltage divider results in larger noise level during resistance monitoring measurements by passing small test currents prior and posterior to the annealing process [see Fig. 4(a) after $800 \mathrm{~ms}$ ]. For the BMGs-heating setup, the sample resistance has much weaker temperature dependence than the heated components. The temporal evolution of resistance, giving an upward slope in the temperature-dependent resistance at the early stages of heating, is mainly dominated by the resistance change in the heated electrodes and sample mounting. Taking the linear part of the temperature-dependent resistance in Fig. 4(a), before $T_{\mathrm{x}}$, gives 

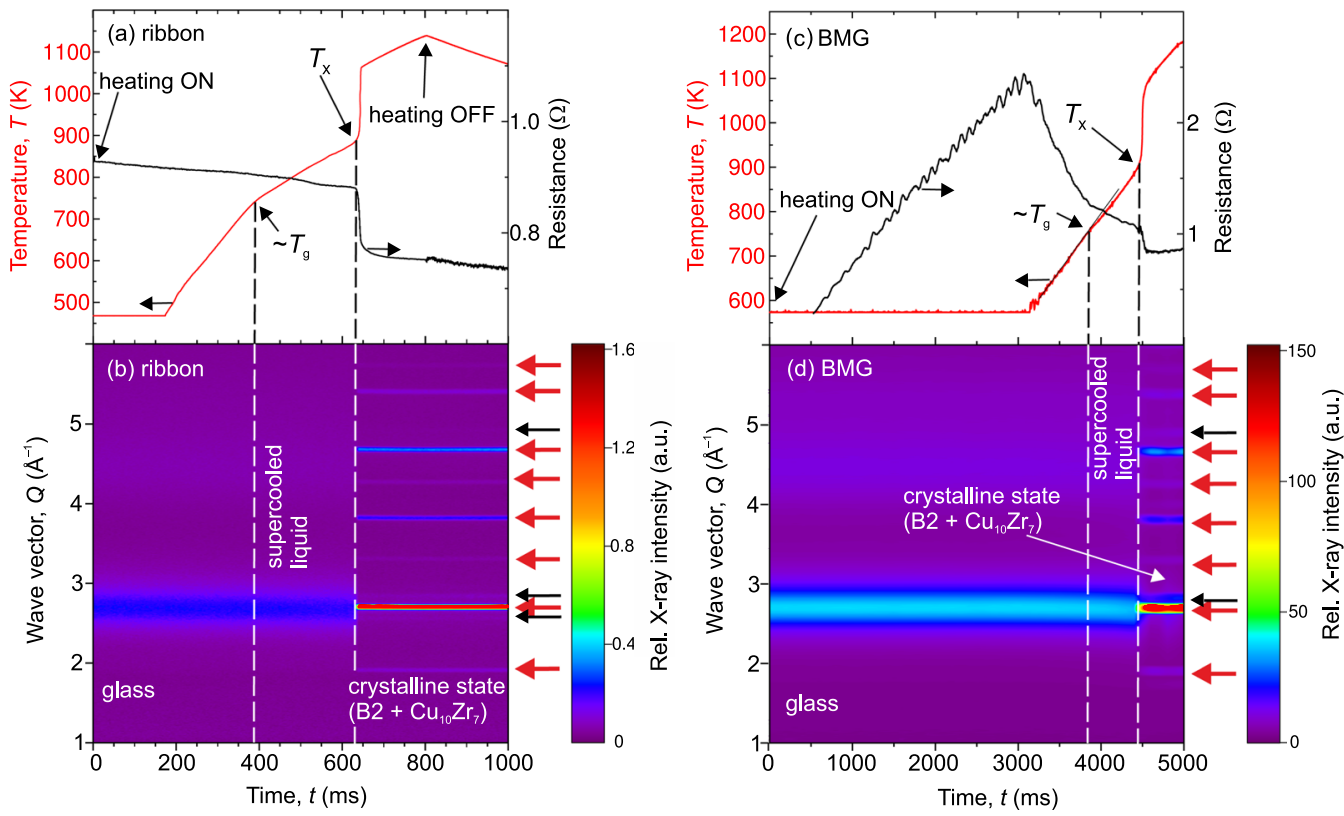

FIG. 4. Time-resolved in situ $\mathrm{x}$-ray diffraction data of $[(\mathrm{a})$ and $(\mathrm{b})]$ the $\mathrm{Cu}_{47.5} \mathrm{Zr}_{47.5} \mathrm{Al}_{4} \mathrm{C}_{0.5}$ glassy ribbon collected at $250 \mathrm{~Hz}$ sampling rate at the P21.1 beamline and those of [(c) and (d)] the $\mathrm{Cu}_{44} \mathrm{Zr}_{44} \mathrm{Al}_{8} \mathrm{Hf}_{2} \mathrm{Co}_{2}$ BMG collected at $100 \mathrm{~Hz}$ at the P02.1 beamline on heating in a vacuum of $\sim 10^{-4}$ mbar. [(a) and (c)] The crystallization onset is detected as the drop and the recalescence event on the time-dependent resistivity and pyrometer temperature, respectively. [(b) and (d)] The integrated intensities of a phase evolution on heating the glass show the existence of three distinct states: (i) the glass, (ii) the supercooled liquid, and (iii) the crystalline state (the red arrows evidence the existence of the B2-CuZr phase, and the minor presence of $\mathrm{Cu}_{10} \mathrm{Zr}_{7}$ phase is indicated by the black arrows-only the most significant peaks are labeled for clarity).

a temperature coefficient of resistance of about $4.1 \times 10^{-5} \mathrm{~K}^{-1}$ for the ribbon. This is two orders of magnitude lower than that for pure copper for which the coefficient is $3.93 \times 10^{-3} \mathrm{~K}^{-1}$. ${ }^{37}$ The resistance of the bulk-metallic glass given in Fig. 4(c) was processed by a Saviztky-Golay method using Origin 2020.

Due to the linear thermal expansion, bending of ribbon in the direction of the $\mathrm{x}$-ray beam occurs upon heating. This results in changing the sample-to-detector distance as well as peak position on measured XRD patterns. For example, a ribbon movement of $5 \mathrm{~mm}$, overestimated value, would cause a peak shift of about $0.015 \AA^{-1}$ in the $Q$-space by measurements at a sample-to-detector distance of $1021 \mathrm{~mm}$ as in the present work. This effect should be kept in mind when interpreting the diffraction data, but it does not obstruct qualitative and quantitative phase analysis.

The temporal evolution of integrated intensities reveals phase transformations on heating for the $\mathrm{Cu}_{47.5} \mathrm{Zr}_{47.5} \mathrm{Al}_{4.0} \mathrm{Co}_{0.5}$ glassy ribbon and for the $\mathrm{Cu}_{44} \mathrm{Zr}_{44} \mathrm{Al}_{8} \mathrm{Hf}_{2} \mathrm{Co}_{2}$ BMG, as shown in Figs. 4(b) and $4(\mathrm{~d})$, respectively. The time-dependent resistance and temperature, measured simultaneously with the x-ray diffraction, are shown in the upper panels of the corresponding parts. The existence of three distinct states can be recognized from the in situ experiments: (i) the glassy state ranging from $0 \mathrm{~ms}$ to $380 \mathrm{~ms}$, from room temperature up to $750 \mathrm{~K}$, for the $\mathrm{Cu}_{47.5} \mathrm{Zr}_{47.5} \mathrm{Al}_{4.0} \mathrm{Co}_{0.5}$ glassy ribbon and from $0 \mathrm{~ms}$ to $3850 \mathrm{~ms}$, from room temperature up to $745 \mathrm{~K}$, for the $\mathrm{Cu}_{44} \mathrm{Zr}_{44} \mathrm{Al}_{8} \mathrm{Hf}_{2} \mathrm{Co}_{2} \mathrm{BMG}$; (ii) the supercooled liquid ranging between $380 \mathrm{~ms}$ and $652 \mathrm{~ms}, 750-890 \mathrm{~K}$, for the $\mathrm{Cu}_{47.5} \mathrm{Zr}_{47.5} \mathrm{Al}_{4.0} \mathrm{Co}_{0.5}$ glassy ribbon and $3850-4950 \mathrm{~ms}$,
745-910 K, for the $\mathrm{Cu}_{44} \mathrm{Zr}_{44} \mathrm{Al}_{8} \mathrm{Hf}_{2} \mathrm{Co}_{2}$ BMG; and (iii) the crystalline state for $t \geq 625 \mathrm{~ms}, T \geq 890 \mathrm{~K}$, for the $\mathrm{Cu}_{47.5} \mathrm{Zr}_{47.5} \mathrm{Al}_{4.0} \mathrm{Co}_{0.5}$ glassy ribbon and $t \geq 4950 \mathrm{~ms}, T \geq 910 \mathrm{~K}$, for the $\mathrm{Cu}_{44} \mathrm{Zr}_{44} \mathrm{Al}_{8} \mathrm{Hf}_{2} \mathrm{Co}_{2} \mathrm{BMG}$ until melting is reached (not shown here).

The crystallization of both samples is dominated by the formation of the $\mathrm{B} 2-\mathrm{CuZr}$ phase [indicated by the red arrows in Figs. 4(b) and 4(d) for the $\mathrm{Cu}_{47.5} \mathrm{Zr}_{47.5} \mathrm{Al}_{4.0} \mathrm{Co}_{0.5}$ glassy ribbon and $\mathrm{Cu}_{44} \mathrm{Zr}_{44} \mathrm{Al}_{8} \mathrm{Hf}_{2} \mathrm{Co}_{2} \mathrm{BMG}$, respectively] accompanied by the formation of the low-temperature $\mathrm{Cu}_{10} \mathrm{Zr}_{7}$ phase [highlighted by the black arrows in Figs. 4(b) and 4(d) for ribbons and BMGs, respectively]. Note that only the most prominent diffraction peaks of both identified phases are marked in Fig. 4. It is the B2 phase that is beneficial to the plasticity of metallic-glass-crystal composites. ${ }^{38}$ For the selected samples studied here, the applied heating rates are sufficiently high to suppress crystallization of the brittle low-temperature phases, such as commonly observed $\mathrm{CuZr}_{2}$, with the minor formation of $\mathrm{Cu}_{10} \mathrm{Zr}_{7}{ }^{13}$ Even with this minor content of the low-temperature $\mathrm{Cu}_{10} \mathrm{Zr}_{7}$ phase, the glass-crystal composite may show considerable amount of ductility.

Because of the controlled heating, glass-crystal composites containing dominantly the B2 phase can be made (Fig. 5). Figure 5(b) shows the integrated intensities of a final glass-crystal composite formed on heating the ribbon in a chamber flushed with $\mathrm{He}$, which gives a higher initial cooling rate of about $1100 \mathrm{~K} \mathrm{~s}^{-1}$, unlike $200-300 \mathrm{~K} \mathrm{~s}^{-1}$ in vacuum. To form a composite, the heating must be stopped just before $T_{\mathrm{x}}$ is reached - which is monitored by the resistivity and pyrometer readings [Fig. 5(a)]. When the glass is 

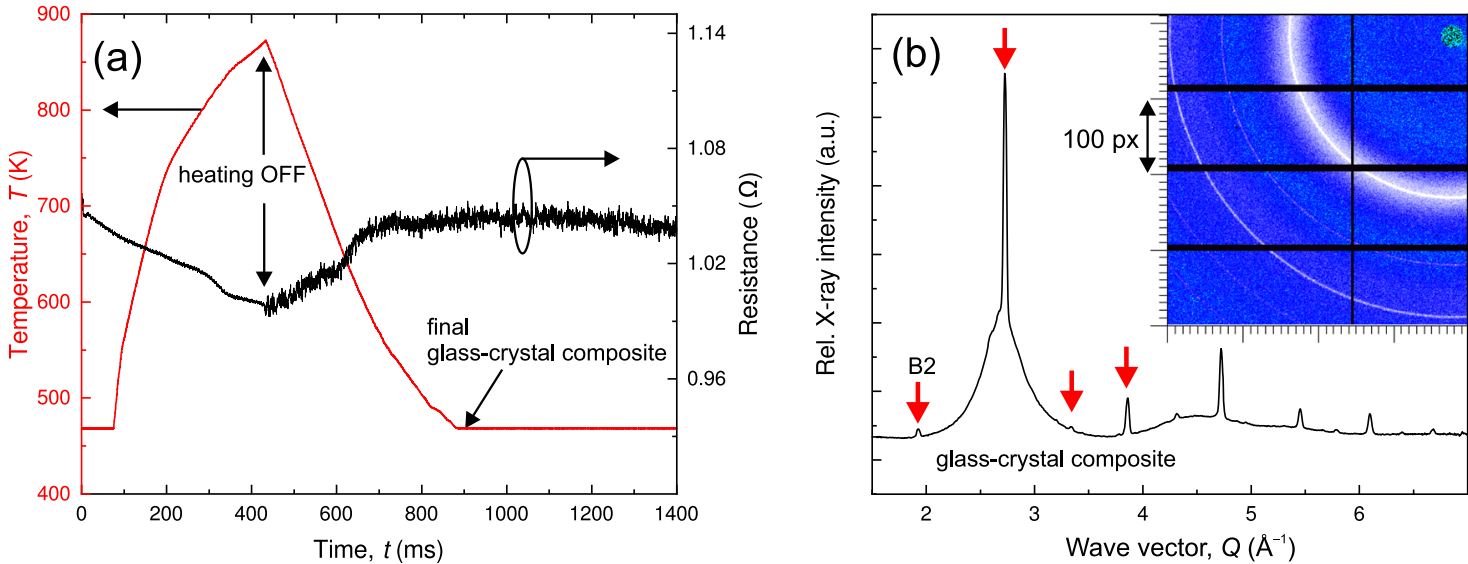

FIG. 5. (a) Temperature evolution (left abscissa) and time-dependent resistivity (right abscissa) of the $\mathrm{Cu}_{47.5} \mathrm{Zr}_{48} \mathrm{Al}_{4.0} \mathrm{Co}_{0.5}$ metallic-glass ribbon heated in a chamber flushed with He to form a glass-crystal composite. (b) Ex situ diffractogram derived from the Dectris PILATUS3 X CdTe 2M detector, collected at $1 \mathrm{~Hz}$ sampling rate, showing the final glass-crystal composite containing the B2-CuZr phase (red arrows; only a few peaks are labeled) measured at the P21.1 beamline. The inset shows part of the 2D recorded pattern by the detector.

heated at or above $T_{\mathrm{x}}$, fast crystallization takes place resulting in fully crystalline samples. A composite composed of the parent glass and dominantly B2 phase [marked by the red arrows in Fig. 5(b)] can readily be resolved. Part of the $2 \mathrm{D}$ scattered pattern is also shown as the inset in Fig. 5(b).

\section{CONCLUSIONS}

Two devices, developed and custom built at the Leibniz Institute for Solid State and Materials Research Dresden, were presented for studying phase transformations in ribbons and bulk-metallic glasses at controlled sample temperature, in terms of heating/cooling rate and ambient atmosphere, by in situ high-energy $\mathrm{x}$-ray diffraction. The case studies were carried out at the beamlines P21.1 and P02.1 at PETRA III, DESY. Both devices are interchangeable at both beamlines. It was demonstrated that the crystallization mechanism on heating can readily be controlled, with typical heating rates up to the range of $\sim 10^{3} \mathrm{~K} \mathrm{~s}^{-1}$ relevant for composite formation, and related to the formation of metallic-glass-crystal composites with enhanced plasticity. The fast-current-heating devices also allow for other fundamental properties of glass-forming liquids to be studied, such as phase transformation diagrams on heating and cooling, crystallization kinetics, in situ structural changes, and relaxation/rejuvenation by thermal cycling through supercooled liquid.

\section{ACKNOWLEDGMENTS}

J.O., I.K., and K.K. acknowledge the financial support by the German Research Foundation DFG (Contract Nos. Ka-3209/9-1 and KO-5771/1-1). We acknowledge the DESY (Hamburg, Germany), a member of the Helmholtz Association HGF, for the provision of experimental facilities. Part of this research was carried out at beamline P02.1 and P21.1 at PETRA III.

We are also very grateful to S. Donath, B. Opitz, and M. Ulbrich (IFW Dresden) for technical support.

\section{DATA AVAILABILITY}

Raw data were generated at the Deutsches ElektronenSynchrotron (DESY) large scale facility. The data that support the findings of this study are available from the corresponding author upon reasonable request.

\section{REFERENCES}

${ }^{1}$ M. F. Ashby and A. L. Greer, Scr. Mater. 54, 321 (2006).

${ }^{2}$ S. V. Ketov, A. S. Trifonov, Y. P. Ivanov, A. Y. Churyumov, A. V. Lubenchenko, A. A. Batrakov, J. Jiang, D. V. Louzguine-Luzgin, J. Eckert, J. Orava, and A. L. Greer, NPG Asia Mater. 10, 137 (2018).

${ }^{3}$ J.-C. Lee, Intermetallics 44, 116 (2014).

${ }^{4}$ P. Ross, S. Küchemann, P. M. Derlet, H. Yu, W. Arnold, P. Liaw, K. Samwer, and R. Maaß, Acta Mater. 138, 111 (2017).

${ }^{5}$ S. Scudino, J. J. Bian, H. Shakur Shahabi, D. Şopu, J. Sort, J. Eckert, and G. Liu, Sci. Rep. 8, 9174 (2018).

${ }^{6}$ K. Kosiba, S. Scudino, R. Kobold, U. Kühn, A. L. Greer, J. Eckert, and S. Pauly, Acta Mater. 127, 416 (2017)

${ }^{7}$ I. V. Okulov, I. V. Soldatov, M. F. Sarmanova, I. Kaban, T. Gemming, K. Endström, and J. Eckert, Nat. Commun. 6, 7932 (2016).

${ }^{8}$ S. Pauly, G. Liu, S. Gorantla, G. Wang, U. Kühn, D. H. Kim, and J. Eckert, Acta Mater. 58, 4883 (2010).

${ }^{9}$ S. Pauly, G. Liu, G. Wang, U. Kühn, N. Mattern, and J. Eckert, Acta Mater. 57, 5445 (2009).

${ }^{10}$ S. Pauly, S. Gorantla, G. Wang, U. Kühn, and J. Eckert, Nat. Mater. 9, 473 (2010).

${ }^{11}$ Y. Wu, H. Wang, H. W. Wu, Z. Y. Zhang, X. D. Hui, G. L. Chen, D. Ma, X. L. Wang, and Z. P. Lu, Acta Mater. 59, 2928 (2011).

${ }^{12} \mathrm{~L}$. Treyachenko, "Al-Cu-Zr (aluminium-copper-zirconium)," in LandoltBörnstein-Group IV Physical Chemistry 11A2 (Light Metal Systems. Part 2), edited by G. Effenberg and S. Ilyenko (SpringerMaterials, 2005), pp. 206-222.

${ }^{13}$ K. Kosiba and S. Pauly, Sci. Rep. 7, 2151 (2017).

${ }^{14}$ I. Kaban, K. Khalouk, F. Gasser, J.-G. Gasser, J. Bednarčik, O. Shuleshova, I. Okulov, T. Gemming, N. Mattern, and J. Eckert, J. Alloys Compd. 615, S208 (2014).

${ }^{15}$ D. V. Louzguine, A. R. Yavari, K. Ota, G. Vaughan, and A. Inoue, J. Non-Cryst. Solids 351, 1639 (2005). 
${ }^{16}$ N. Mattern, H. Hermann, S. Roth, J. Sakowski, M.-P. Macht, P. Jovari, and J. Jiang, Appl. Phys. Lett. 82, 2589 (2003).

${ }^{17}$ A. R. Yavari, R. Barrue, M. Harmelin, and J. C. Perron, J. Magn. Magn. Mater. 69, 43 (1987).

${ }^{18}$ T. Kulik, D. Bucka, and H. Matyja, J. Mater. Sci. Lett. 12, 76 (1993).

${ }^{19}$ G. Kaltenboeck, M. D. Demetriou, S. Roberts, and W. L. Johnson, Nat. Commun. 7, 10576 (2015).

${ }^{20}$ S. Küchemann and K. Samwer, Acta Mater. 104, 119 (2016).

${ }^{21}$ W. L. Johnson, G. Kaltenboeck, M. D. Demetriou, J. P. Schramm, X. Liu, K. Samwer, C. P. Kim, and D. C. Hofmann, Science 332, 828 (2011).

${ }^{22}$ S. Küchemann, P. M. Derlet, C. Liu, D. Rosenthal, G. Sparks, W. S. Larson, and R. Maaß, Adv. Funct. Mater. 28, 1805385 (2018).

${ }^{23}$ S. Küchemann, G. Gibbins, J. Corkerton, E. Brug, J. Ruebsam, and K. Samwer, Philos. Magn. Lett. 96, 454 (2016).

${ }^{24}$ S. Brauer, D. H. Ryan, J. O. Ström-Olsen, M. Sutton, and G. B. Stephenson, Rev. Sci. Instrum. 61, 2214 (1990).

${ }^{25}$ M. Kopcewicz, E. Jackiewicz, L. Załuski, and A. Załuska, J. Appl. Phys. 71, 3997 (1992).

${ }^{26}$ J. Bednarcik, M. Cesnek, and P. Sovak, J. Magn. Mang. Mater. 499, 166282 (2020).

${ }^{27}$ D. H. Bilderback, P. Elleaume, and E. Weckert, J. Phys. B: At., Mol. Opt. Phys. 38, S773 (2005).
${ }^{28}$ A.-C. Dippel, H.-P. Liermann, J. T. Delitz, P. Walter, H. Schulte-Schrepping, O. H. Seeck, and H. Franz, J. Synchrotron Radiat. 22, 675 (2015).

${ }^{29}$ F. Marlton, O. Ivashko, M. von Zimmermann, O. Gutowski, A.-C. Dippel, and M. R. V. Jørgensen, J. Appl. Cryst. 52, 1072 (2019).

${ }^{30}$ K. R. Lim, W. T. Kim, E.-S. Lee, S. S. Jee, S. Y. Kim, D. H. Kim, A. Gebert, and J. Eckert, J. Mater. Res. 27, 1178 (2012).

${ }^{31}$ A. P. Hammersley, S. O. Svensson, A. Thompson, H. Graafsma, Å. Kvick, and J. P. Moy, Rev. Sci. Instrum. 66, 2729 (1995).

${ }^{32}$ A. P. Hammersley, S. O. Svensson, M. Hanfland, A. N. Fitch, and D. Häusermann, High Press. Res. 14, 235 (1996).

${ }^{33}$ A. P. Hammersley, ESRF Internal Report, ESRF98HA01T, FIT2D V9.129 Reference Manual V3.1, 1998.

${ }^{34}$ See https://confluence.desy.de/display/FSEC/Scientific+Software\#ScientificSoft ware-p02_processing_tool for information about the used software; accessed on February 20, 2020.

${ }^{35}$ Q. Cheng, X. Han, I. Kaban, I. Soldatov, W. H. Wang, Y. H. Sun, and J. Orava, Scr. Mater. 183, 61 (2020).

${ }^{36}$ Y. Miao, R. Villarreal, A. Talapatra, R. Arróyave, and J. J. Vlassak, Acta Mater. 182, 29 (2020).

${ }^{37}$ J. M. Eargle, Electroacoustical Reference Data (Springer, Boston, MA, 1994), pp. 106-107.

${ }^{38}$ J. Orava, I. Kaban, M. Benkocka, X. Han, I. Soldatov, and A. L. Greer, Thermochim. Acta 677, 198 (2019). 